\title{
Anticipating by Pigeons Depends on Local Statistical Information in a Serial Response Time Task
}

\author{
Alyson L. Froehlich \\ University of Utah
}

\author{
Walter T. Herbranson \\ Whitman College
}

\author{
Julia D. Loper, David M. Wood, and Charles P. Shimp \\ University of Utah
}

\begin{abstract}
Pigeons responded in a serial response time task patterned after that of M. J. Nissen and P. Bullemer (1987) with humans. Experiment 1 produced global facilitation: Response times in repeating lists of locations were faster than when locations were random. Response time to a spatial location was also a function of both that location's 1st- and 2nd-order local predictability, in rough agreement with the Hick-Hyman law, according to which response time is a linear function of amount of information. Experiment 2 showed that both local and global facilitation is limited to moderate response-to-stimulus intervals of about 0.50 to $2.00 \mathrm{~s}$. Experiment 3 showed that response time did not depend on global statistical information. Overall, local and global performances depended on local statistical information, but global performance did not depend on global information. Local facilitation was interpreted in plain English as anticipating.
\end{abstract}

Behavior depends on statistical information in the environment. Indeed, Estes (2002) noted that "there can be few cognitive activities as pervasive and adaptive in ordinary life as assessing the probabilities of alternative outcomes" (p. 8), and other researchers have suggested that adult humans, children, and infants may use similar statistical learning mechanisms (Hunt \& Aslin, 2001, p. 661). One naturally wonders whether some nonhuman animals, which obviously also need to assess the probabilities of alternative outcomes, may use these same mechanisms.

A task that is prominent in the clarification of human statistical learning mechanisms is the serial response time task. A recent cognitive and neurobiological discussion of serial response times noted that "the ability to produce and learn sequential actions is one of the hallmarks of human cognition. Indeed, this ability has

Alyson L. Froehlich, Julia D. Loper, David M. Wood, and Charles P. Shimp, Department of Psychology, University of Utah; Walter T. Herbranson, Department of Psychology, Whitman College.

This research was supported in part by a grant from the University of Utah Research Committee to Charles P. Shimp and a National Research Service Award predoctoral fellowship to Walter T. Herbranson. We thank Greg Leigh for his excellent help in running some of the animals and analyzing some of the data. We also thank our colleagues Sarah Creem, Frank Drews, Ray Kesner, and Dave Strayer for enlightening conversations about various aspects of spatial attention, spatial memory, and serial response time performances. We are especially indebted to Fran Friedrich, who read a draft of this article and made many greatly appreciated suggestions for improvement and clarification. We also thank Frances Knapp, who always managed to blend just the right amount of light-hearted humor with her otherwise serious, careful, prompt, edifying secretarial help.

Correspondence concerning this article should be addressed to Charles P. Shimp, Department of Psychology, University of Utah, 380 South 1530 East, Room 502, Salt Lake City, UT 84112-0251. E-mail: charlie.shimp@ psych.utah.edu been hypothesized to constitute a fundamental adaptation that characterizes what makes human cognition so extraordinary" (Keele, Ivry, Mayr, Hazeltine, \& Heuer, 2003, p. 316). We think that the ability of many nonhuman animals to learn and produce sequential actions similarly makes animal cognition extraordinary (Hulse, 1978; Shimp, 1976; Terrace, 2001). The present article, therefore, describes a new method for the quantitative analysis of nonhuman animal serial response times. Although Fountain (1990), Machado (1994), Shimp (1973), and Terrace (2001), among others, have developed a variety of other methods to address sequential pattern learning in animals, we are inclined to believe our new task has some powerful advantages because, to anticipate our results, we show that it can generate much data in a short time, involves simple and easy pretraining, and provides a new form of quantitative evidence with which to test the generality of existing claims about how nonhuman animal performance is sensitive to statistical information in the environment.

The method we developed is an avian adaptation of the serial response time method first used by Nissen and Bullemer (1987) to study differences between performances by neurologically intact humans and humans with amnesia. Nissen and Bullemer used a between-groups design in which human participants responded in a serial response time task related to tasks described by Garner (1962). On each trial, a light appeared at one of four locations, and a participant was instructed to press the key below the lit location. Response time was measured from the onset of the light at a spatial location to a participant's response to the corresponding key. For one group, the locations in which the light appeared occurred in a repeating 10-item sequence. For another group, the order of the locations in which the light appeared was random. Participants in the group with a structured list responded faster on average to cued locations than those in the group with random order. This overall facilitation of response times for the group with the structured list, 
which defines global facilitation, was Nissen and Bullemer's chief support for their claim that participants learned something about a list. The Nissen and Bullemer task has subsequently been used successfully in neuropsychological research on attention and memory (e.g., Curran, 1998; Keele et al., 2003; Knopman \& Nissen, 1987, 1991; Nissen, Knopman, \& Schacter, 1987; Vakil, Kahan, Huberman, \& Osimani, 2000).

Curran, Smith, DiFranco, and Daggy (2001) suggested that global facilitation shows researchers little about what is actually learned in the Nissen and Bullemer (1987) task: The simple difference between average reaction time in structured and random conditions may not suffice to describe sequential pattern learning. Curran et al. used two different structured lists and showed that sequence learning depends on sequence structure: Different lists produced different patterns of response times over the various serial positions. In general, Curran et al.'s participants appeared to learn a good deal about the likelihood with which a spatial location occurred given the last one or two locations, and that learned information correspondingly affected the speed with which a participant responded to a target location given the last one or two locations. Other recent evidence supports Curran et al.'s view that serial response times of adult humans are sensitive to local statistical information in repeating structured lists of discriminated spatial locations (Hunt \& Aslin, 2001). Like Curran et al., Hunt and Aslin (2001) showed that humans respond more quickly to locations that can be more accurately predicted on the basis of the most recent one or two locations. This phenomenon may be called local facilitation.

Herbranson (2000) was to our knowledge the first to adapt the Nissen and Bullemer (1987) task for use with nonhuman animals, specifically, with pigeons. We adapted his task to discover to what kinds of statistical information performance was sensitive. Specifically, our goal was to answer four questions about sensitivity of response times to statistical information in sequential patterns. First, can pigeons display the traditional human phenomenon of global facilitation in which average response times in structured lists are faster than in unstructured lists (Nissen \& Bullemer, 1987)? If the answer were yes, then pigeons would have been shown to display the same phenomenon that has made the Nissen and Bullemer task useful in human cognitive and neuropsychological research. We agree with Hunt and Aslin (2001), however, that global facilitation does say little about what a subject actually learns about the sequential structure of a list. Therefore, our second question is can pigeons also display local facilitation? Can their response times display a sensitivity to local statistical information, specifically, to the likelihood of the spatial location given the previous location or locations, as was the case with humans in Curran et al. (2001) and in Hunt and Aslin? If the answer were again yes, then it would have been shown that pigeons as well as humans are sensitive to the local statistical information in sequential pattern learning. Third, do the answers to the first two questions depend on such temporal features of the serial response time task as the spacing between successive spatial locations to which a subject responds? A yes answer would suggest possible roles for temporal processes such as working memory for recent locations and/or the dynamics of spatial attention in avian serial response time performances, as has been suggested for corresponding human performances. Fourth, does global statistical information about a location, in the absence of local statistical information, facilitate response time to that location? A yes answer would suggest that similar statistical learning mechanisms operate for both local and global information.

\section{General Method}

\section{Subjects}

Fourteen male White Carneaux pigeons (Columba livia) were obtained from the Palmetto Pigeon Plant (Sumter, SC). Each was maintained at approximately $80 \%$ of its free-feeding weight, with supplemental Western Sun Pigeon Feed provided as needed following daily experimental sessions. The pigeons were housed individually, in standard pigeon cages with free access to water and grit, in a colony room with a 14:10-hr light-dark cycle. All sessions took place at approximately the same time 4 to 6 days a week.

\section{Apparatus}

Five standard three-key Lehigh Valley Electronics pigeon chambers were multiplexed to an IBM PS/2 model 95 computer that arranged all the experimental contingencies and recorded the data. Within each chamber, the three keys were arranged in a horizontal row approximately $24 \mathrm{~cm}$ above the floor. The center (C) key was located directly above the food hopper. The middle of the left $(\mathrm{L})$ and right $(\mathrm{R})$ keys was approximately 8 $\mathrm{cm}$ to the $\mathrm{L}$ and $\mathrm{R}$ of the middle of the $\mathrm{C}$ key. Each key could be individually illuminated with white light. Reinforcement consisted of access to mixed grain presented in the food hopper. Ventilator fans and white noise helped in masking extraneous sounds. A house light remained on during the entire experiment, except during reinforcement.

\section{Procedure}

There were 750 discrete trials per daily session. Each trial consisted of a response-to-stimulus (RS) interval, the illumination of one of the three white keys, and a corresponding peck to that key. The single, illuminated key remained illuminated until pecked. A single peck either initiated an RS interval, which was $0.50 \mathrm{~s}$ (except in Experiment 2 in which it was varied), or a reinforcer consisting of access to mixed grain. Reinforcer duration was usually $2.10 \mathrm{~s}$ but was varied for some pigeons, by no more than $\pm 0.30 \mathrm{~s}$, to maintain individual pigeons' weights. The three keys were on the average equally likely to be illuminated, except in Experiment 3 (in which base rates were varied). Each peck to an illuminated key was reinforced according to a random ratio 20. Pecks to dark keys had no programmed consequences. In Experiment 1, the modal frequency of dark key pecks per trial was zero, and the corresponding mean and standard error were 2.1 and 0.5 , respectively. Pecks to dark keys were not recorded in Experiments 2 and 3 .

Pilot data (Herbranson, 2000) suggested that 20 days of training was probably more than sufficient to produce approximately steady state performance in structured conditions with unfamiliar lists. Pilot data also suggested performance stabilized more quickly in the unstructured task. Unstructured conditions were therefore generally run for fewer days than structured conditions. Otherwise, condition duration depended on experimenter availability or, in the case of Condition 1 of Experiment 2, on the completion of data analysis software.

\section{Experiment 1}

Nissen and Bullemer (1987) interpreted global facilitation, faster response times in structured than in random tasks, to imply that humans learned something about the structured sequence. Nissen and Bullemer assumed that this global facilitation reflected a person's preparing, either peripherally or centrally, for expected locations. Experiment 1 therefore first asked whether pigeon subjects would produce global facilitation. To explore the generality 
of any global facilitation we found, we used several different structured lists. We also asked more specifically how pigeons' response times were sensitive to the statistical likelihood of a spatial location given the locations of the previous one or two serial positions. In short, Experiment 1 posed the first two of the four questions in this study: Can the human phenomenon of global facilitation be obtained with the pigeon, and are pigeons' serial response times sensitive to local statistical information?

\section{Method}

Subjects. The 4 pigeons were experimentally naive. Pretraining consisted of successive habituation to the chamber, magazine training, and autoshaping.

Apparatus and procedure. The apparatus was as described in the General Method section. Table 1 summarizes the experimental conditions. Each condition involved either a structured or a random sequence of illuminated spatial locations. The stimulus locations for the structured tasks appeared in a repeating sequence with nine serial positions. Table 1 shows how the list was varied over conditions, with the first structured condition (Condition 1) involving a list of the nine successive locations consisting of LLLCRCRCR, the second structured condition (Condition 3) involving a list of LLLCCCRRR, and so on. In each structured condition, after the ninth serial position, the entire 9-location list was repeated again and continued to repeat until all 750 locations had been presented. In structured conditions, daily sessions began at randomly selected, equally likely serial positions.

We constructed lists so that over conditions there were serial positions having varying degrees of predictability, provided that a pigeon's memory extended no farther back than the most recent one or two serial positions (numerical examples are provided below in the Results section). In random conditions, lit keys appeared in random and equally likely spatial locations: Each location was selected randomly without regard to previous locations.

Initially, structured and random conditions were alternated. Later, we judged that sufficient data from random conditions had been acquired, and, therefore, we conducted only structured conditions.

\section{Results}

Response times to the first nine locations in a session were omitted from analyses to avoid including warm-up effects, and similarly, response times occurring to the first nine locations after the delivery of reinforcement were omitted to reduce the effects of pauses that sometimes occur after reinforcement on random ratio schedules.

Table 1

Experimental Conditions for Experiment 1

\begin{tabular}{ccc}
\hline Condition no. & No. of days & \multicolumn{1}{c}{$\begin{array}{c}\text { Structure of } \\
\text { 9-serial-position list }\end{array}$} \\
\hline 1 & 20 & LLLCRCRCR \\
2 & 10 & Random \\
3 & 20 & LLLCCCRRR \\
4 & 10 & Random \\
5 & 20 & CCCLLLRRR \\
6 & 10 & Random \\
7 & 20 & LLLCRCCRR \\
8 & 20 & LLCCRRCLR \\
9 & 20 & LRCCLRLRC \\
10 & 20 & RRRCLCLCL \\
11 & 20 & LCRLRCRLC \\
\hline
\end{tabular}

Note. $\mathrm{L}=$ left; $\mathrm{C}=$ center; $\mathrm{R}=$ right.
Global facilitation was obtained: The mean of the eight mean response times from the eight structured conditions was significantly faster than the mean of the three mean response times from the three unstructured conditions, $t(9)=2.70, p<.02$. (All reported $p$ values for the $t$ statistic are two-tailed, and all alpha levels are .05, two-tailed, unless otherwise stated.) Effect size was moderately large, with $r=.669$. (All reported effect sizes for $t$ tests are in terms of "effect size $r$ " [Dunn, 2001, p. 389].) However, examination of individual performances showed that 1 of the pigeons, Pigeon 4, was slower in five of the structured conditions than in the unstructured condition in which it was fastest, so it probably is not the case, despite the reliable facilitation based on group averages, that all individual pigeons display global facilitation. Results described below suggest, interestingly, that Pigeon 4 may actually have been most sensitive to list structure. The answer to our first question is, in any case, a qualified yes: Global facilitation in an avian serial response time task can be obtained, if only at the level of average performance, which we note, is the criterion conventionally used in the human literature to define global facilitation (Nissen \& Bullemer, 1987).

Figure 1 displays conventional serial position curves. It shows mean median response time for the 4 pigeons and the last 5 days of a condition, plotted as a function of the nine serial positions, for each condition. (It should be recalled that the first and ninth positions in Figure 1 usually do not represent the first and ninth positions on any 1 day, because a list began each day in a random serial position.) Visual inspection of Figure 1 suggests that response time depended on serial position.

A one-way analysis of variance (ANOVA) with repeated measures was performed on each of the structured conditions, first with alpha equal to .05 and then with an alpha corrected for multiple tests equal to .0064 (Bonferroni correction; Hays, 1973, p. 299). Structured conditions $(1,3,5,7,8,9,10$, and 11) gave $F(8,27)=$ $4.491,3.643,4.037,1.564,2.751,9.390,6.861$, and 2.784, respectively. Using alpha equal to .05 , there was a reliable serial position effect in Structured Conditions 1, 3, 5, 8, 9, 10, and 11. Using the corrected alpha for multiple tests, there was still a reliable serial position effect in Conditions 1, 5, 9, and 10, in which all $p$ values were .01, and effect size $f$ (Cohen, 1992, p. 157) was large (Cohen, 1992), 1.014, 0.902, 1.209, and 1.410, respectively. Because only one reliable $F$ using the corrected alpha suffices to reject the null hypothesis of no overall serial position effect, that hypothesis was rejected.

Figure 2 shows mean median response time as a function of first-order local predictability, which is the likelihood that a location comes next given the previous location (Curran et al., 2001; Hunt \& Aslin, 2001). It was computed as follows. In Condition 1 in which the list was LLLCRCRCR, the relative frequency of $\mathrm{R}$ given a preceding $\mathrm{C}$ was 3 out of 3 , and the first-order local predictability of an $\mathrm{R}$ given a previous $\mathrm{C}$ was therefore 1.00. Similarly, the relative frequency of $\mathrm{L}$ given a preceding $\mathrm{L}$ was 2 out of 3, for a first-order local predictability of .67. Similarly, given $\mathrm{L}$, there was a relative frequency of 1 out of 3 that the next location was C. Serial Positions 1 and 4 accordingly had first-order local predictability values of 1 out of 3 ; Serial Positions 2, 3, 6, and 8 had first-order local predictability values of 2 out of 3 ; and Positions 5, 7, and 9 had first-order local predictabilities of 1.00.

Similarly, examination of the list in Condition 3, LLLCCCRRR, shows that Serial Positions 1, 4, and 7 had first-order local predictability values of 1 out of 3, and Serial Positions 2, 3, 5, 6, 8, 

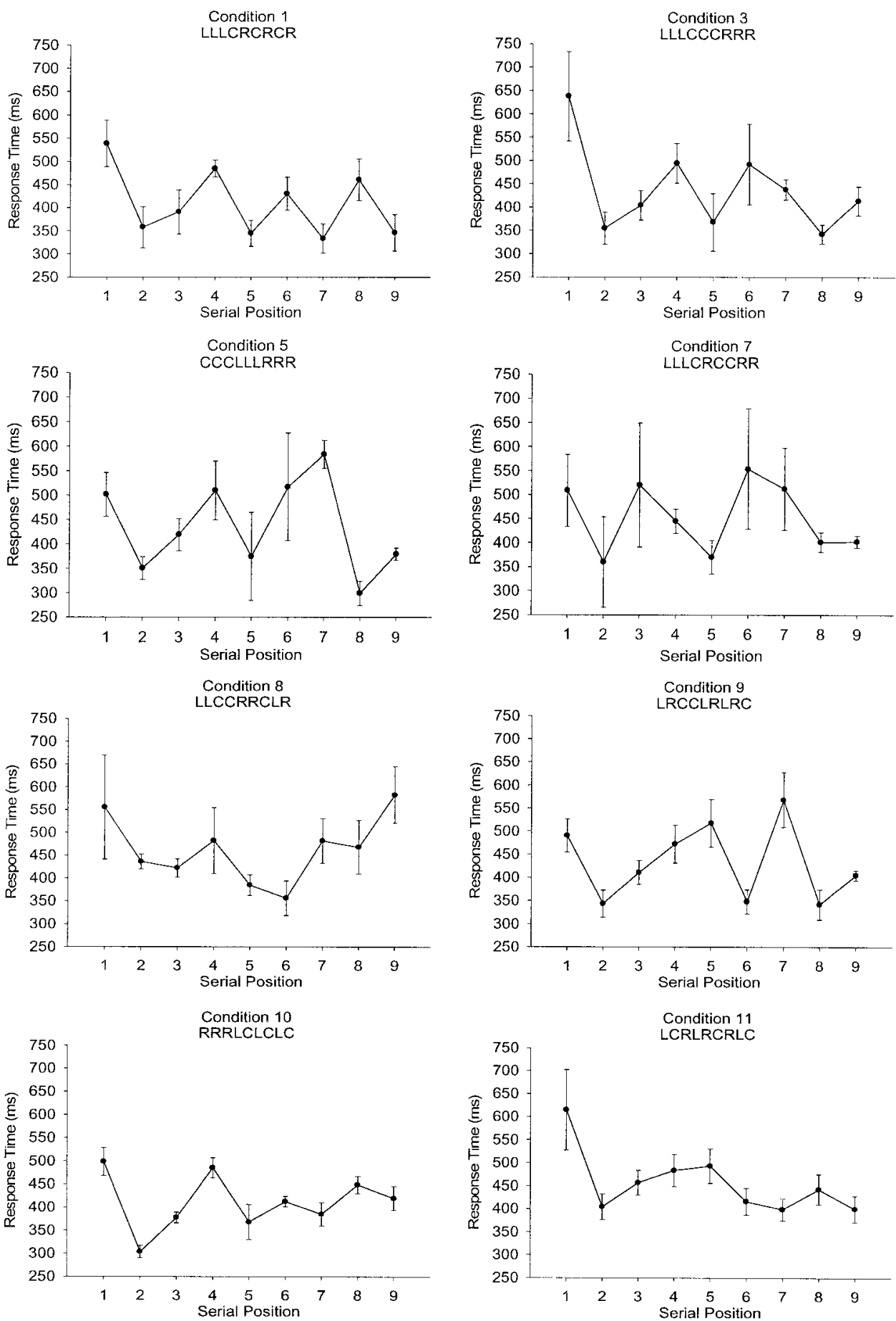

Figure 1. Mean median response time to respond to a cued location averaged over the 4 pigeons and the last 5 days of a condition, as a function of the serial position of that location in a nine-serial-position repeated list, for each structured condition in Experiment 1. Each serial position curve shows performance in one structured condition, indicated by the corresponding list. Vertical lines correspond to plus or minus one standard error. $\mathrm{L}=$ left; $\mathrm{C}=$ center; $\mathrm{R}=$ right.

and 9 had first-order local predictability values of 2 out of 3 . In this manner, a local predictability can be assigned to each serial position in each condition. These values varied, across conditions and serial positions, from .33 , which corresponds to chance because there were three spatial locations, through .67 , to 1.00 , which corresponds to certainty. In unstructured conditions, local predictability was always .33 , or chance, equal to the overall or global likelihood of any spatial location. 
A

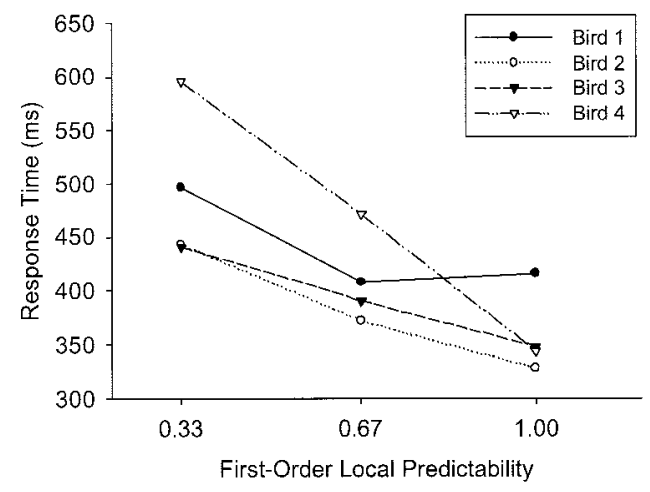

B

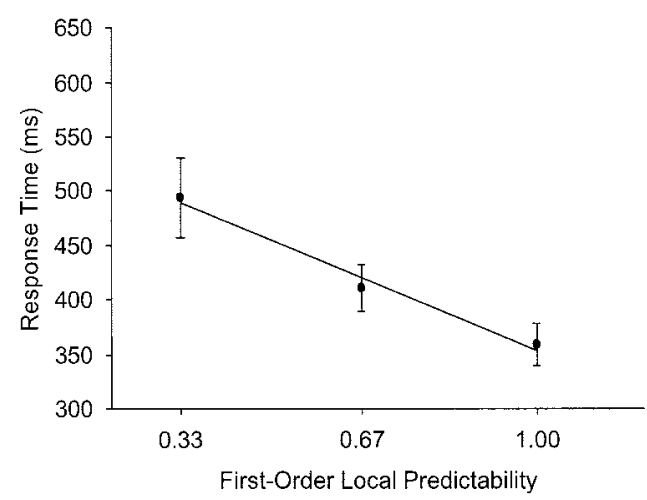

Figure 2. A: Mean median response time to respond to a cued location for individual pigeons, averaged over the last 5 days of conditions, as a function of first-order local predictability. Each point reflects the average response time, across all conditions, to any serial position having the indicated first-order local predictability, in Experiment 1. (See text for details.) B: Mean median response time to respond to a cued location, averaged over the last 5 days of conditions and the 4 pigeons, and the best-fitting least-squares straight line (see text for parameter values). Error bars show plus or minus one standard error across pigeons.

Figure $2 \mathrm{~A}$ shows mean median response time for each individual pigeon, and Figure $2 \mathrm{~B}$ shows the 4-pigeon average response time, plotted as a function of these three values of first-order local predictability, in all eight structured conditions. Visual inspection of Figure 2 suggests response time was a decreasing function of first-order local predictability: the less uncertainty about the next location, the faster the response to it. Notice that Pigeon 4, which was unique in not displaying reliable global facilitation, showed the biggest effect on response time of changes in local predictability. A one-way ANOVA with repeated measures verified that response time depended on local predictability, $F(2,9)=10.800$, $p<.01$, and the effect size, $f$, was large, 1.201. Post hoc Newman-Keuls tests showed that response times at .33 (chance) were slower than at $.67(p<.05)$ and at 1.00 (certainty; $p<.01)$ but that response times at .67 were not slower than at $1.00(p>$ $.05)$.

Figure 2B also shows the linear regression line for the group average: The slope was -202.0 , the $y$ intercept was 555.7, and $r^{2}$ was .581. Although the small number of values of the independent variable, only three, obviously precludes any strong support for linearity, we would be remiss if we failed to note that the function has a somewhat linear appearance, and the linear regression line accounts for a reasonably high percentage of the variance. In any case, Figure 2 gives a clear answer to our second question. Yes, the local structure of a list has a systematic effect on response time: Pigeons are sensitive to the first-order local statistical information in a list.

Because first-order local predictability effects were large and systematic, and perhaps even at least roughly approximated by a linear function, it is natural to ask whether higher order predictability effects could also be described in correspondingly elegant terms. Figure 3 shows response time as a function of second-order predictability for each of the two values of first-order predictability, .33 and .67: These two values are the only values for which the eight lists permitted functions to be calculated. The top four panels of Figure 3 show individual mean median response times over the last 5 days of conditions, with data from serial positions with first-order local predictability equal either to .33 or to .67 , represented as filled and open circles, respectively. Data points for serial positions with first-order local predictability equal to 1.00 are represented by filled triangles. The bottom panel shows the corresponding average data and associated linear regression lines. Second-order local predictability, the likelihood of a location given the previous two locations, was computed in the following manner. In the list LLLCRCRCR, for example, the second-order local predictability of the first serial position is .33 because $\mathrm{L}$ follows the sequence of CR once out of three instances of CR. Notice that in some cases, a two-item sequence occurs only once, so that the location that follows it must necessarily have a second-order local predictability of 1.00. In the example provided, the pair LC occurs once so that the location that follows it, $\mathrm{R}$, has a second-order local predictability of 1.00. The bottom panel in Figure 3 shows the average results along with corresponding linear regression lines. Visual inspection of Figure 3 suggests that response time was a generally decreasing function of second-order local predictability and that the function is roughly linear for both first-order local predictability of .33 and .67. The two estimated regression lines gave slopes of -96.8 and $-114.2, y$ intercepts of 562.5 and 498.9, and $r^{2}$ s of .178 and .283 , for first-order values of .33 and .67 , respectively. Thus, the slope indicating the rate at which secondorder information is processed is similar for the two different values of first-order local predictability. These slopes suggest that increases in second-order local predictability produced faster average response times for both values of first-order local predictability, and this suggestion is confirmed by a one-way ANOVA with repeated measures for the fixed first-order value of $.33, F(2$, $9)=10.556, p<.01$, with a large effect size of .473 , and similarly for $.67, F(2,9)=9.724, p<.01$, with a large effect size of .640 . Thus, response time reliably decreased, in a roughly linear fashion, as a function of second-order local predictability, for each of two fixed values of first-order local predictability.

Figure 4 shows mean median response time at serial positions having chance values of first-order local predictability, .33, in three different contexts consisting of (a) specific serial positions in structured lists in which some but not all serial positions had first-order local predictabilities equal to .33 , (b) the one-structured list (Condition 8) in which all nine serial positions had first-order local predictabilities equal to .33 , and (c) random conditions in which all locations were equally likely throughout a session. 

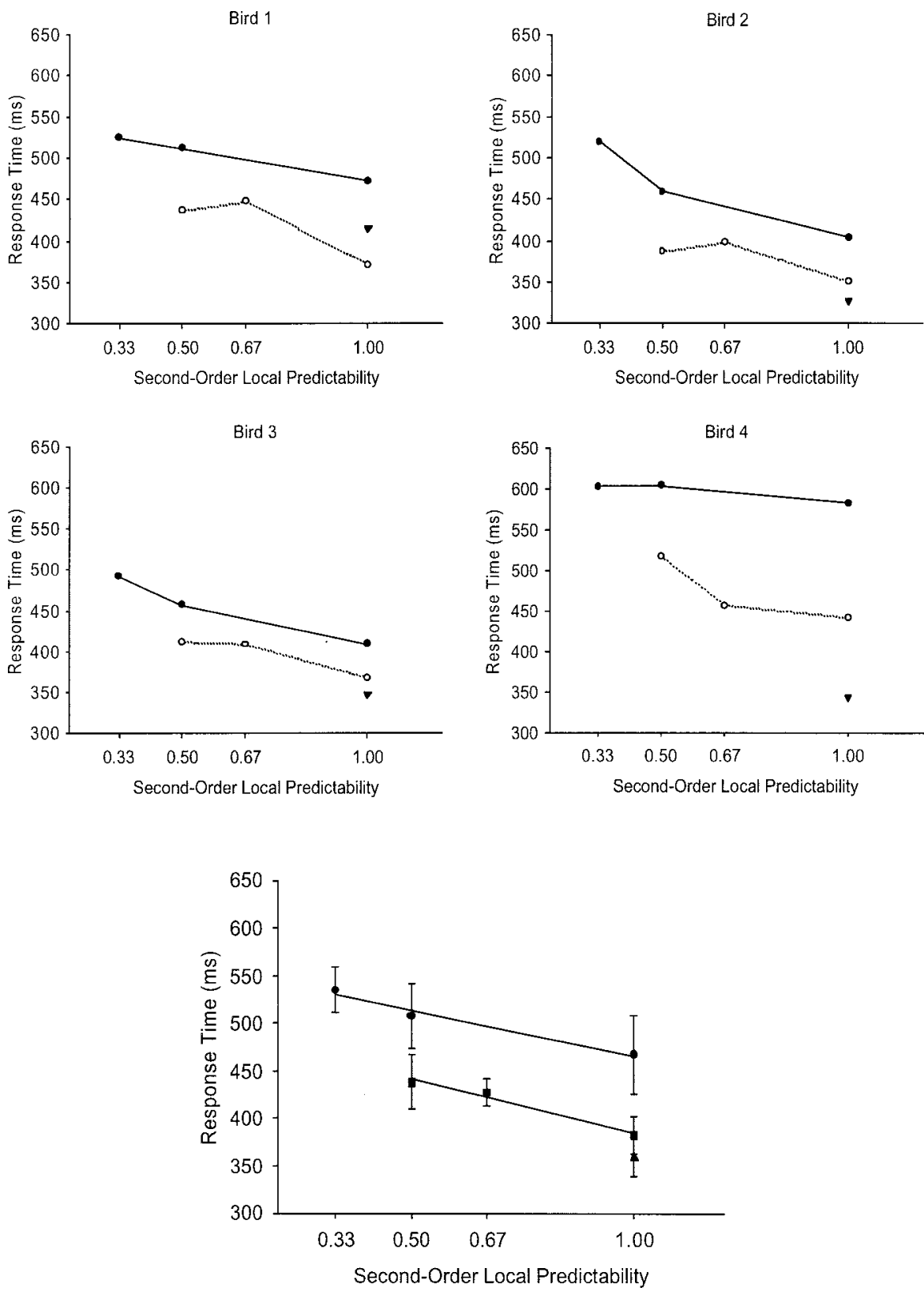

Figure 3. Four top panels show mean median response time to respond to a cued location for individual pigeons, averaged over the last 5 days of conditions, as a function of second-order local predictability, for three different values of first-order local predictability, $.33, .67$, and 1.00. Bottom panel shows mean median response time to respond to a cued location, averaged over the last 5 days of conditions and the 4 pigeons, and the best-fitting least-squares straight line (see text for parameter values). Data from serial positions with first-order local predictability equal to .33 and .67 are represented as filled circles and open circles (or filled squares), respectively. Data for serial positions with first-order local predictability equal to 1.00 are represented by filled triangles. Error bars show plus or minus one standard error across pigeons.

Visual inspection suggests, and a one-way ANOVA with repeated measures shows, $F(2,9)=0.758, p<.51$, that there was no reliable difference in response time to chance locations in these three different contexts. This similarity is interesting in view of the fact that it interrelates the local effect on response time of a specific value of a local predictability in a structured list with the corresponding global effect in a random condition. The similarity suggests numerically equal local and global predictability values might have equal effects on response time.

\section{Discussion}

Experiment 1 provisionally answered our first two questions and, to our surprise, revealed a striking but unanticipated role for 


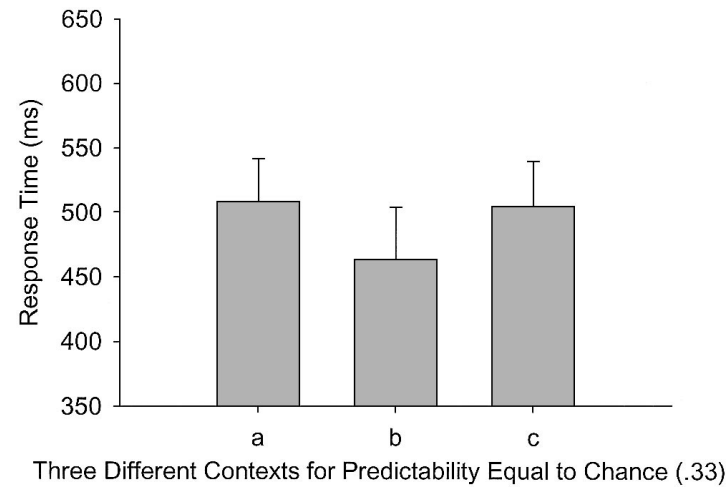

Figure 4. Mean median response time averaged over 4 pigeons and the last 5 days of conditions to locations having three different kinds of predictability equal to .33 (chance): (a) structured conditions with some serial positions with first-order local predictability equal to .33 , (b) a structured condition (Condition 8) with all serial positions with first-order local predictability equal to .33 , and (c) unstructured conditions with global predictability equal to .33 , in Experiment 1 . There was no reliable difference among the effects of the three types of chance predictabilities. Error bars show plus or minus one standard error across pigeons.

some long-established theoretical ideas in human information processing. First, the between-conditions effect known as global facilitation, according to which responding is faster in structured lists than in random conditions, was reliably obtained at the level of group average performance. One pigeon, however, more often responded faster in unstructured than in structured conditions. The pigeon that failed to reliably demonstrate global facilitation also showed, however, the biggest effect of local predictability, so that the absence of global facilitation for that pigeon may have resulted from its very slow response times to serial positions having the lowest predictability (which happened to equal chance). In any case, overall, there was a reliable global facilitation effect, and Nissen and Bullemer (1987) took global facilitation to be a defining feature of their human participants having learned at least something about list structure in a structured condition. This global criterion applied to our data implies that on the average pigeons learn something about the difference between structured and random lists of spatial locations but says nothing about what that something is. This standard by which sequential pattern learning can be defined, crude as it is, is still useful and is sufficient to discriminate among neuropsychological theories of human memory (e.g., Keele et al., 2003). The present results show that pigeons also show sequential pattern learning by this same criterion.

Second, our local analysis shows more clearly what pigeons learn in the serial response time task: The second main finding is what to our knowledge is the first demonstration in either the human or the nonhuman animal literature that response time to a spatial location in a repeating list, as in the Nissen and Bullemer (1987) task, is a decreasing function, perhaps a linearly decreasing function, of both first- and second-order local predictability. Experiment 1 showed that providing a pigeon with more information, hence less uncertainty, about the likelihood of the next location in a serial list facilitated the pigeon's responding to that location, in a systematically increasing manner. These results correspond to those of Hick (1952) and Hyman (1953; see Welford, 1968, for a review), who successfully predicted that, on the assumption that information was processed at a constant rate, human response time in several settings, similar but not identical to the present task, would be a linearly increasing function of uncertainty.

This qualitative similarity between pigeon and human serial response time performances provides a comparative perspective on neuropsychological and cognitive theories. These theories (e.g., Keele et al., 2003) are often in terms of human brain regions and cognitive processes, such as prefrontal cortex and declarative memory, about which much remains to be understood as they apply to pigeons. Yet, the similarity between pigeon and human serial response time performances may be more than qualitative in nature. Figure 5 compares how humans and pigeons are sensitive to local statistical information. We were able to compare only first-order effects because of the manner in which analogous human results were reported. We first visually estimated response times to different first-order likelihoods for the last sessions from Hunt and Aslin's (2001) Figure 2 (p. 664), Figure 3 (p. 667), and Figure 7 (p. 672) for their Experiments 1, 2, and 3, respectively, and then computed a linear regression line for these combined data (slope $=-152, y$ intercept $=447, r^{2}=.85$ ). Figure 5 shows these human data along with the pigeon results from Figure 2 . We then performed an analogous comparison for the data in Figure 2A in Curran et al. (2001, p. 153), who reported difference scores relating response time to targets with first-order local predictability of .33 and .67 in structured tasks to targets in unstructured tasks. We calculated a linear regression line with slope $=-97$ and $y$ intercept $=50$. (Figure 5 does not show these results because they are on a different scale, because they are difference scores, not response times.) From these two previous studies, with estimated slopes of -152 and -97 , one would tentatively conclude that human serial response time decreases as local predictability increases. Nissen and Bullemer (1987, p. 25) provided data from their Experiment 4 from which one may determine whether they too obtained a functional relation between response time and first-order local predictability. We calculated the average response

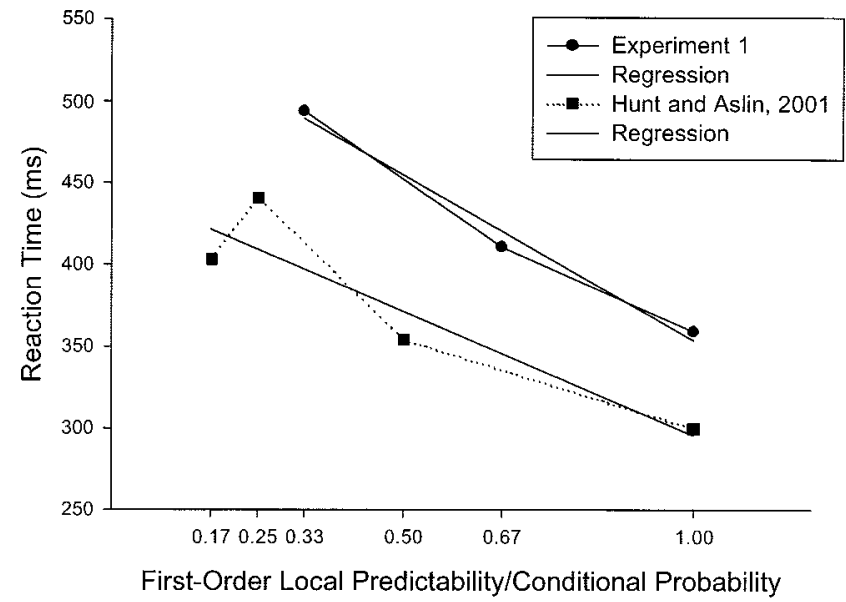

Figure 5. Average response time of pigeons as a function of first-order local predictability in Experiment 1 (filled circles) and average response time of humans as a function of conditional probability, estimated from Figures 2, 3, and 7 in Hunt and Aslin (2001, pp. 664, 667, and 672, respectively). Also shown are linear regression lines (see text for parameter values). Pigeons responded slower but processed information at roughly the same rate as reflected in similar overall slopes. 
time difference for the possible first-order local predictabilities and found no such relation. Average response time differences of $-205 \mathrm{~ms},-108 \mathrm{~ms}$, and $-195 \mathrm{~ms}$ were calculated for first-order local predictabilities of $.33, .50$, and .67 , respectively. The absence of an orderly function may simply reflect their participants' relatively limited amount of exposure to the repeating list and hence to the statistical evidence. In their Experiment 4, participants experienced only 400 trials, in comparison with 3,360 to 3,840 trials experienced by Hunt and Aslin's (2001) participants and 1,200 trials by Curran et al.'s (2001) participants. In comparison, our pigeons experienced 15,000 trials.

We tentatively conclude the following. First, human data, like ours, show that response time is a decreasing function of first-order local predictability, provided that ample exposure to statistical information is provided to the participants. Second, the slopes relating response time to local predictability, -202 for pigeons, -152 for Hunt and Aslin's (2001) participants, and -97 for Curran et al.'s (2001) participants, are sufficiently similar that additional comparative research is clearly merited. From the perspective of the Hick-Hyman law, similar slopes are assumed to reflect similar speeds of processing information, so that one could speculate that in this context, human and pigeon processing speeds are well within an order of magnitude of each other. Although the many procedural differences among the three experiments make detailed comparisons of slopes premature, we, as pigeon researchers, cannot fail to note that visual inspection of Figure 5 suggests that the processing speed for pigeons appears no less than that for humans. Given the sensitivity of the Hick-Hyman law to many procedural details (Welford, 1968), we hasten to note that the similarity in processing between humans and pigeons may not hold up under more comprehensive comparison: Data from carefully matched tasks obviously are needed.

It is instructive to compare local facilitation effects in avian serial response time tasks with local sequential priming effects in avian visual search. A phenomenon called a runs advantage may be obtained when the same target is presented successively over several trials in a visual search task. Under certain conditions, response time to detect a specific target is faster when that target is more probable (P. M. Blough, 1996, 1997). This result resembles the dependency of response time on amount of information in what may be interpreted as sequential priming in the present experiment, in the sense that in both cases, response time is faster when immediately preceding stimuli provide greater information with which the next target may be predicted. Visual search and serial response time tasks thus appear to provide converging evidence on sequential priming phenomena.

Finally, we note that the similarity between first- and secondorder functions in our data encourages a future search for even more remote influences on response time to a target location. We suspect, however, that the effects of higher orders of predictability would be better examined in the context of an entirely different methodology. The standard method in the human neuropsychological literature, on which the present experiments are based, is not well suited to examining that issue, as discussed in some detail by Hunt and Aslin (2001).

\section{Experiment 2}

Experiment 2 addressed our third question: Do the local and global facilitation effects discovered in Experiment 1 depend on time? The corresponding human literature leans heavily on the use of RS intervals within a narrow range of 0.50 to $1.00 \mathrm{~s}$ (Curran et al., 2001; Hunt \& Aslin, 2001; Nissen \& Bullemer, 1987), and some evidence suggests global facilitation may be reduced in magnitude at RS intervals of 1.50 to $2.00 \mathrm{~s}$ (Frensch \& Miner, 1994; Stadler, 1995; Willingham, Greenberg, \& Thomas, 1997). There are many reasons why facilitation effects we obtained in Experiment 1 might depend greatly on time. Among these reasons are the following three. First, if facilitation in the Nissen and Bullemer (1987) procedure were due chiefly to the establishment in long-term memory of a motor program, then the RS interval might affect asymptotic performance because many theories of associative learning and conditioning assume a transfer of information held in working memory to associative memory so that longer RS intervals might reduce the likelihood that a working memory representation could be successfully transferred to associative memory. Second, the idea of a motor program requires both the establishment of a representation of a temporal pattern and a decoding algorithm by which this representation is implemented in real time (Welford, 1968, 1977), so that even if a pigeon after making a response to one location successfully retrieved an appropriate associative memory involving the next likely response location, longer RS intervals might be expected to reduce a pigeon's ability to maintain the recalled local predictability in working memory throughout the RS interval, and therefore less able to effectively anticipate the next location (for related ideas, see Terrace, 2001). Third, if facilitation depends on sustained attention to a spatial location (Shimp \& Friedrich, 1993), then longer RS intervals might involve processes similar to longer values of stimulus onset asynchrony (SOA), the time between onsets of cue and target in a spatial attention task. In the present case, SOA would be the time between the onset of one spatial location on one trial and the onset of the next spatial location on the next trial. The SOA has a large effect on spatial attention, so that once again, we would expect RS interval to affect facilitation effects.

In summary, we hypothesized for any or all of the above reasons that increasing the RS interval would generally reduce the size of both local and global facilitation effects. We also hypothesized that extremely short RS intervals might be a special case and might reduce facilitation effects because an adequate motor program, to use the phraseology of Nissen and Bullemer (1987), might simply be impossible to develop if required retrieving, decoding, and behaving consumed more time than very short RS intervals permit.

\section{Method}

Subjects. All 5 pigeons had previous experimental history responding in a similar task (Herbranson, 2000).

Apparatus and procedure. The apparatus was as described in the General Method section. Table 2 shows the conditions for Experiment 2. As in Experiment 1, there were two kinds of tasks: structured and unstructured. The stimuli for all structured conditions appeared in a nine-item repeating sequence consisting of the successive locations CLRCRLRCL. The list was selected to have an equal base rate for the three different stimuli, and two different values of first-order local predictability, .33 and .67. Table 2 shows that the RS interval was varied over conditions from a minimum of $0.25 \mathrm{~s}$ to a maximum of $8.00 \mathrm{~s}$, with both structured and random conditions conducted at each RS interval. 
Table 2

Experimental Conditions for Experiment 2

\begin{tabular}{rrlr}
\hline $\begin{array}{c}\text { Condition } \\
\text { no. }\end{array}$ & $\begin{array}{c}\text { No. of } \\
\text { days }\end{array}$ & $\begin{array}{c}\text { Structured or } \\
\text { random }\end{array}$ & $\begin{array}{c}\text { Response-to-stimulus } \\
\text { interval (s) }\end{array}$ \\
\hline 1 & 151 & Structured & 1.00 \\
2 & 16 & Structured & 2.00 \\
3 & 25 & Structured & 4.00 \\
4 & 12 & Random & 2.00 \\
5 & 10 & Random & 0.50 \\
6 & 20 & Structured & 0.50 \\
7 & 16 & Random & 4.00 \\
8 & 15 & Structured & 8.00 \\
9 & 10 & Random & 8.00 \\
10 & 20 & Structured & 0.25 \\
11 & 10 & Random & 0.25 \\
12 & 10 & Random & 1.00 \\
\hline
\end{tabular}

\section{Results}

Results for Experiment 2 are presented as averages over the last 10 days of a condition, unless otherwise noted. We averaged over the last 10 days instead of 5 days for two reasons. First, manipulating RS interval seemed to be the rough equivalent of manipulating the retention interval in a short-term memory experiment, such as delayed matching to sample, and therefore required relatively less associative learning compared with that required by learning statistical information, as in Experiment 1 (and as in Experiment 3, which follows). Performance earlier in a condition therefore was appropriate to include in the condition average. Second, 10 days provided a larger sample of data. All 10 days of unstructured conditions lasting 10 days were included in condition averages because initial data analysis suggested the effects of changing RS interval were for all intents and purposes immediate, implying the effects of RS were perhaps more directly on a pigeon's short-term ability to remember recent locations than on the subsequent effects on long-term associative memory. As in Experiment 1, response times from the first nine items of a session and from the first nine items after reinforcement are deleted from the analysis.

Figure 6 shows mean median response time as a function of serial position, for Structured Conditions 6 and 8 with RS intervals of $0.50 \mathrm{~s}$ and $8.00 \mathrm{~s}$, respectively. Conditions 6 and 8 were selected to show one condition, Condition 6 , in which the RS interval was equal to the most common value in the corresponding human literature, $0.50 \mathrm{~s}$ in which it was expected that response times would show facilitation, and another condition, Condition 8 , in which the RS interval was so long that facilitation was not expected to occur.

Perhaps the most obvious feature of Figure 6 is that local response time was much longer when the RS interval was $8.00 \mathrm{~s}$ than when it was $0.50 \mathrm{~s}$. Visual inspection of Figure 6 suggests also that when the RS interval was $0.50 \mathrm{~s}$, local response time varied as a function of serial position, but that when it was $8.00 \mathrm{~s}$, it did not. A one-way ANOVA with repeated measures for an RS interval of $0.50 \mathrm{~s}$ confirms this possibility, $F(8,36)=4.930, p<$ .01 , with a large effect size of .845. A corresponding ANOVA for an RS interval of $8.00 \mathrm{~s}$ confirms the absence of a reliable dependency of response time on serial position, $F(8,36)=0.616, p>$ .76 .

Figure 7 shows how global response time in structured and

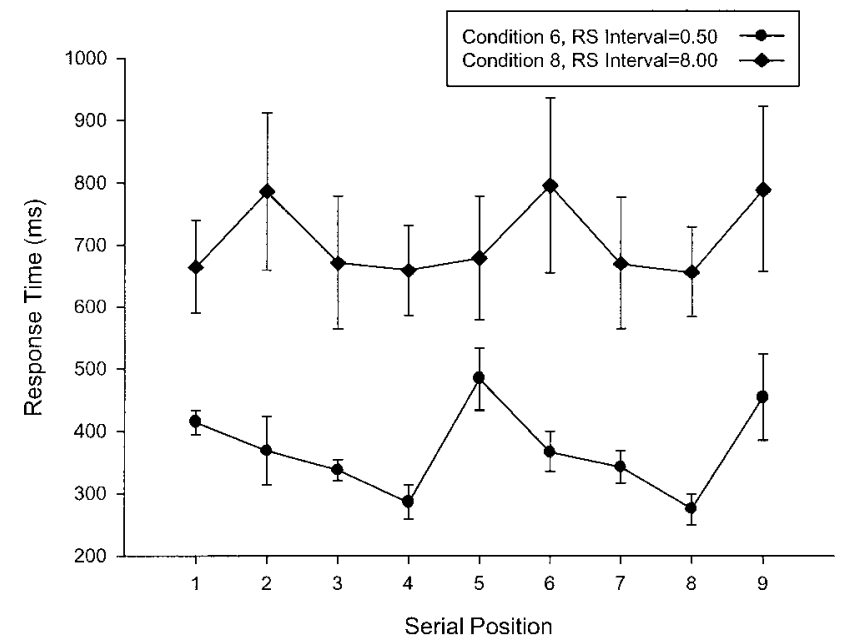

Figure 6. Mean median response time to respond to a cued location, averaged over the last 10 days of a condition and the 5 pigeons, as a function of the serial position of that location in a nine-item repeated list, for response-to-stimulus (RS) intervals of $0.50 \mathrm{~s}$ and $8.00 \mathrm{~s}$, in Experiment 2. Error bars reflect plus or minus one standard error.

unstructured conditions depended on the RS interval. Visual inspection of Figure 7 suggests that global facilitation may have been obtained in Experiment 2 for RS intervals of 0.50, 1.00, and $2.00 \mathrm{~s}$. Paired $t$ tests confirmed this possibility: Reliable global facilitation was obtained at RS intervals of $0.50 \mathrm{~s}, t(4)=6.38, p<$ $.01 ; 1.00 \mathrm{~s}, t(4)=4.10, p<.02$; and $2.00 \mathrm{~s}, t(4)=3.17, p<.03$. Effect sizes were large in all three cases, with $r=.954, .899$, and .846 , respectively.

Figure 8 shows mean median response time as a function of RS interval, for serial positions having the two possible different values of first-order local predictability, .33 and .67. Visual inspection suggests local facilitation may have been obtained at RS intervals of 0.50 and $1.00 \mathrm{~s}$. Paired $t$ tests confirmed this possibility: Reliable differences between response times to serial positions

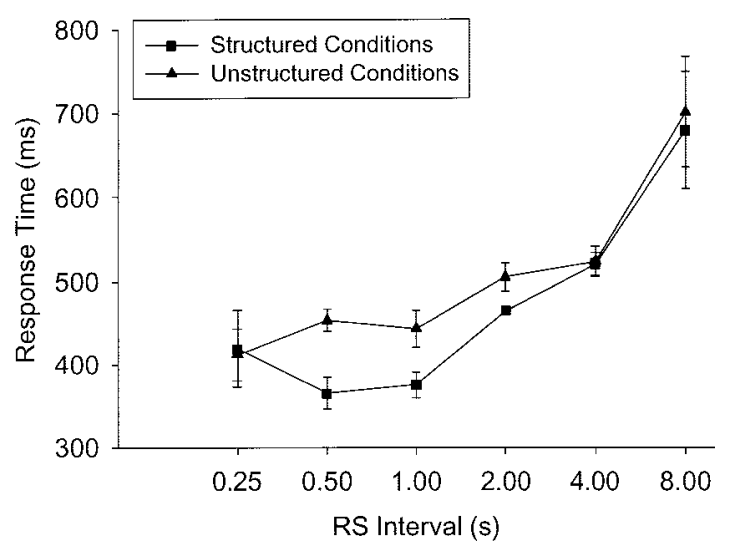

Figure 7. Global mean median response time to respond to a cued location, averaged over the last 10 days of a condition and the 5 pigeons, as a function of the logarithm of the response-to-stimulus (RS) interval, in Experiment 2. Error bars reflect plus or minus one standard error. Reliable global facilitation was obtained when the RS interval was $0.50,1.00$, and $2.00 \mathrm{~s}$. 


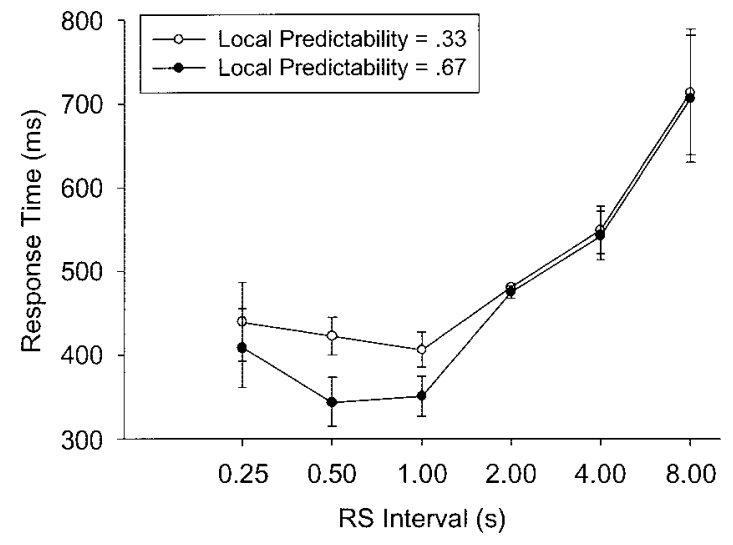

Figure 8. Mean median response time to respond to a cued location, averaged over the last 10 days of a condition, the 5 pigeons, and serial positions having a first-order local predictability equal to the chance value of .33 (open circles corresponding to average response time to Positions 1 , 5 , and 6 ) or to the value halfway between chance and certainty, .67 (filled circles corresponding to average response time to Positions 2, 3, 4, 7, 8, and 9), respectively, as a function of the logarithm of the response-to-stimulus (RS) interval, in Experiment 2. Error bars reflect plus or minus one standard error. Reliable local facilitation was obtained at RS intervals of 0.50 and $1.00 \mathrm{~s}$.

with first-order local predictability of .33 and .67 were obtained at RS intervals of $0.50 \mathrm{~s}, t(4)=4.31, p<.01$, and $1.00 \mathrm{~s}, t(4)=7.02$, $p<.01$. Effect size was large in both cases, with $r=.907$ and .962 , respectively.

Figure 9 shows both response times to serial positions having first-order local predictability values of .33 in structured conditions and overall response times in random conditions, as a function of $\mathrm{RS}$ interval. If a pigeon's memory in the structured task was restricted to the most recent location, then there should be no difference between response time in the two difference cases, with local and global predictability equal to .33 . In both cases, from the pigeon's perspective, the likelihood of any given location given the previous location was .33. If a pigeon's memory extended beyond the previous location, then one might expect a pigeon to be able to predict the next item in the structured condition better than in the random condition, even if the first-order local predictability in the structured condition was equal to the chance value of .33. In short, Figure 9 lets us see whether a global predictability of .33 due to equal base rates of three different locations in a random condition produces response times similar to those produced by a first-order local predictability of .33 within a structured list. Visual inspection of Figure 9 suffices to show that the two curves are qualitatively very similar and hence that predictability of .33 generally produces similar response times regardless of whether that value derives from global predictability in a random list or first-order local predictability in a structured list.

\section{Discussion}

Experiment 2, like Experiment 1, produced global facilitation when the RS interval was about $0.50 \mathrm{~s}$. Experiment 2 also replicated the first-order local facilitation seen in Experiment 1, provided that the RS interval was the same as, or similar to, that in Experiment 1 (i.e., about $0.50 \mathrm{~s}$ ). Experiment 2 also replicated the link found in Experiment 1 between local and global analyses: A chance predictability of .33 had roughly equivalent effects regardless of whether the value of .33 was defined in local or global terms. First-order local predictability equal to chance, .33 , in the context of specific serial positions in structured conditions, and global predictability equal to chance, .33 , in the context of random conditions, generated similar response times.

Perhaps most important, Experiment 2 clarified the temporal context within which the local facilitation observed in Experiment 1 can be obtained: It can be obtained when the RS interval is 0.50 to 1.00 or perhaps $2.00 \mathrm{~s}$ but not when it is either shorter than $0.50 \mathrm{~s}$ or longer than $2.00 \mathrm{~s}$. As predicted, therefore, local facilitation depends on time.

We think it is noteworthy that the RS intervals that we found to be most effective in producing avian facilitation effects are exactly the same as those that produce the greatest global facilitation in the human literature (Stadler, 1995; Willingham et al., 1997). There are many striking similarities between pigeon and human visual cognition (D. S. Blough, 1984; Cook, 2001), and the present results suggest that there may be an additional similarity in terms of local temporal dynamics of serial response time performances. This similarity in the dynamics of serial response time performances strengthens the likelihood that the neurobiological foundation of, and evolution of, human attentional processes can be studied indirectly through the use of invasive techniques with pigeons.

Experiment 2 displayed two different forms of temporal dynamics. First, as discussed above, local facilitation was limited to a specified temporal region. Second, overall response time continued to increase as the RS interval was lengthened to the maximum value explored here, $8.00 \mathrm{~s}$. The two different temporal functions presumably reflect different psychological processes. We think the first function is likely to reflect a form of sustained attention, either peripheral or central, to the information provided by the most recent spatial location about the next location (Curran et al., 2001;

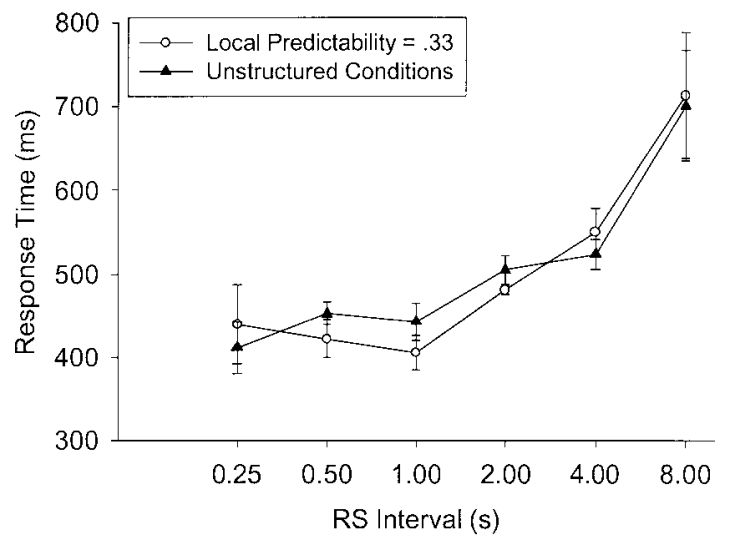

Figure 9. Mean median response time to respond to a cued location, averaged over the last 10 days of a condition and the 5 pigeons, for serial positions having a first-order local predictability of .33 in structured conditions (open circles corresponding to Positions 1, 5, and 6) or a global predictability of .33 in unstructured conditions (filled triangles corresponding to Positions 2, 3, 4, 7, 8, and 9), as a function of the logarithm of the response-to-stimulus (RS) interval, in Experiment 2. Error bars reflect plus or minus one standard error. There was no reliable difference between the effects of local and global types of chance predictabilities. 
Hunt \& Aslin, 2001; Nissen \& Bullemer, 1987). The restricted temporal duration of this phenomenon, scarcely longer than $2.00 \mathrm{~s}$, makes it unlikely that this is a process purely of working memory. The second function, however, may reflect any of several attentional, memory, or timing processes. First, it might involve a kind of behavioral equivalent of short-term memory in which it is not unusual for pigeons, as well as of course humans, to be able to remember stimuli after retention intervals significantly longer than $2.00 \mathrm{~s}$ (Maki, Moe, \& Bierley, 1977). Second, it could reflect a general alerting effect found by Shimp and Friedrich (1993) in a spatial attention experiment. Thus, it may be that very long times between cue and target make pigeons lose attention to the entire task, not just to the specific serial position of a spatial location in a list. Third, it could reflect the fact that timing becomes less precise at longer intervals, so that response times at long RS intervals reflect less memory for the previous location, less sustained attention to the predicted next location, and less certainty about when the next stimulus will occur.

\section{Experiment 3}

Experiments 1 and 2 suggested that global and first-order local likelihoods equal to chance, .33 , did not have different effects: Global response times when all three base rates were equal to .33 were not different from local response times, in structured conditions, at serial positions having first-order likelihoods equal to .33 . Experiment 3, therefore, asked whether numerically equal local and global likelihoods of a spatial location would generally affect response time in similar ways. We varied global likelihoods of spatial locations within unstructured conditions, with response location on one trial providing no local information about response location on the next.

Intuitively, one might predict that a subject in an unstructured condition with unequal base rates would respond more quickly to a spatial location that occurs more frequently than another, for basically the same reason that it responds more quickly to a more likely location due to local predictability: More information about the next location is provided in either case, thereby providing an animal a better opportunity to either centrally or peripherally prepare for it. Thus, Experiment 3 varied base rates of spatial locations, and instead of looking for a dependency of response time on local sequential patterning, here we looked for a dependency on global predictability.

Experiment 3 therefore addressed our fourth and last question: Does the manipulation of global statistical information affect overall response time to that location? If pigeons were equally sensitive to local and global statistical information, then results from Experiments 1 and 2 would predict that global response time at a spatial location in Experiment 3 would be a linearly decreasing function of the global likelihood of that location. Roughly analogous human literature offered only an ambiguous prediction for the outcome of Experiment 3, with some evidence predicting that base rate would have a large effect on response time (Shaw \& Shaw, 1977) and other evidence predicting that base rate might have little or no effect (Hunt \& Aslin, 2001; Posner, Snyder, \& Davidson, 1980).

\section{Method}

Subjects. All 5 pigeons were experimentally naive.

Apparatus and procedure. The apparatus was as described in the General Method section. Table 3 shows how base rates were varied over
Table 3

Experimental Conditions for Experiment 3

\begin{tabular}{ccccc}
\hline $\begin{array}{c}\text { Condition } \\
\text { no. }\end{array}$ & $\begin{array}{c}\text { No. of } \\
\text { days }\end{array}$ & \% left & \% center & $\%$ right \\
\hline 1 & 10 & 33 & 33 & 34 \\
2 & 15 & 80 & 10 & 10 \\
3 & 22 & 98 & 1 & 1 \\
4 & 16 & 1 & 1 & 98 \\
5 & 20 & 10 & 10 & 80 \\
6 & 19 & 25 & 25 & 50 \\
7 & 41 & 10 & 80 & 10 \\
8 & 21 & 5 & 5 & 90 \\
9 & 25 & 49 & 2 & 49 \\
\hline
\end{tabular}

conditions. It shows the probabilities with which, in any condition, any specific key was illuminated on any trial. As in the unstructured conditions in Experiments 1 and 2, the probability of a location on a trial was constant and independent of the location on the previous trial: As in the unstructured conditions in Experiments 1 and 2, the appearance of a lit key in a location did not provide any additional information about the likelihood of the subsequent location, beyond the information already provided by global base rate.

\section{Results}

Figure 10 shows mean median response time as a function of spatial location, for each condition. Visual inspection of Figure 10 suggests that although absolute durations of response times drifted over conditions as they not uncommonly do, because of drifts in response topography (D. S. Blough, 1972), base rate of occurrence of a location had no discernible effect on response times to that location. Comparing Figure 10 with Table 3, showing the probabilities of the three locations in each condition, reveals no systematic relation between response time to a location and its global base rate of occurrence. A one-way ANOVA with repeated measures was not significant for any condition, $F(2,8)=1.336,0.415$, $2.172,0.991,0.664,0.651,0.428,1.094$, and 0.253 , for Conditions 1 to 9 , respectively. Corresponding $p$ values were $.32, .67, .18, .41$, $.54, .55, .67, .38$, and .78 for Conditions 1 to 9 , respectively. Pigeons ignored the information in the global likelihood of a spatial location.

\section{Discussion}

Experiments 1 and 2 found no difference between effects on response time of the same chance value, .33, of local and global likelihoods. We naturally wondered whether this equivalence generalized to numerical values other than that equal to chance. Would statistical information conveyed through global versus local likelihoods have generally equivalent effects? To answer this question, Experiment 3 varied global likelihood of a spatial location to determine whether the effect on response time might be similar to the effect of local likelihood in Experiments 1 and 2. It was not. Not only was global response time at a location not a systematically decreasing function of the global likelihood of that location, global base rate had no discernible effect on response speed. This result is roughly analogous to other cases of base-rate neglect and has interesting theoretical implications. First, base-rate neglect is surprising from the perspective of rational behavior, according to which a pigeon should presumably respond faster to a location that 


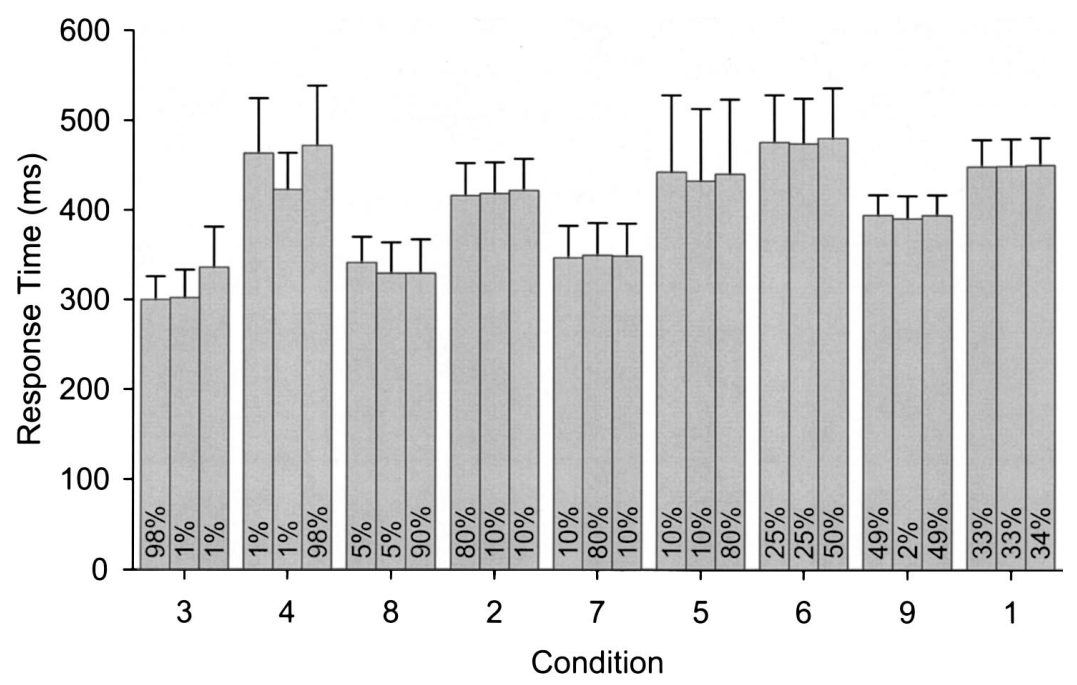

Figure 10. Mean median response time to respond to a cued location, averaged over the last 5 days of a condition and the 5 pigeons, as a function of the three spatial locations (left, center, and right), for each condition in Experiment 3 in which global base rate of spatial locations was varied over conditions. There was no reliable effect of global base rate. Error bars show plus or minus one standard error across pigeons.

occurs more often and hence for which the pigeon is more likely to be prepared. In Experiment 3, for example, one might have expected a pigeon to adopt a posture from which it could on the average more quickly respond to a more likely location.

Second, the result shows a surprising lack of sensitivity to global statistical information, when contrasted with the considerable sensitivity pigeons displayed to local information in Experiments 1 and 2. Experiment 3 is not alone, however, as a case in which subjects are irrational by ignoring global base rates. In the human literature, irrational base-rate neglect is perhaps most familiar in categorical judgment (e.g., see Tversky \& Kahneman, 1990) but is also seen in serial response time tasks in which insensitivity is displayed to overall frequencies of occurrence of pairs of target locations, in comparison with sensitivity to first-order local predictability (Hunt \& Aslin, 2001). Base-rate neglect has also been displayed by pigeons in tasks other than serial response time tasks, including delayed matching to sample (Zentall \& Clement, 2002).

Thus, the present base-rate neglect is consistent with previous evidence that it is possible for base rate to be irrationally neglected. It is natural to ask why pigeons ignore global base rate despite the fact that they do not ignore local structure. Two plausible reasons can apparently be rejected. First, one might suggest that the reason why pigeons ignored base rate is that the random ratio 20 contingency did not vary as a function of spatial location, and hence not as a function of base rate. That is, no matter what the base rates that determined how a pigeon responded to the different locations, its payoff remained the same. One could therefore conclude that this constancy of reward across locations explains the constancy of response time across locations. However, this random ratio schedule was also constant across locations and across different serial positions in Experiments 1 and 2 in which responding did depend on local properties of list structure, so that this possible explanation apparently can be rejected. Second, one might suppose that the reason why global base rate had no effect was that the pigeons' training with structured lists required the pigeons to pay attention to local rather than to global variables. However, the pigeons in
Experiment 3 were experimentally naive and had never been exposed to structured lists, so that possible explanation can also be rejected. It seems safest at present simply to note that avian serial response time performance is not sensitive to base rate.

Nissen and Bullemer (1987) suggested that the motor program responsible for superior performance on a structured list compared with that on a random task involved spatial attention to the next expected location, sustained over the RS interval. It is therefore of some interest to compare the lack of base rate effects in Experiment 3 with the base-rate effects observed in a spatial attention experiment with pigeons (Shimp \& Friedrich, 1993). In their experiment, a brief visual cue on an L or R key probabilistically predicted the location of an L or R target key appearing $400 \mathrm{~ms}$ later, a peck on which delivered reinforcement. Varying base rates of occurrence of predictive $\mathrm{L}$ and $\mathrm{R}$ cues produced an effect. Shimp and Friedrich (1993) did not vary target base rates for nonpredictive cues, however, so their procedure was importantly different from that of Experiment 3. Thus, Shimp and Friedrich's base-rate effects actually support the results from the present Experiments 1 and 2 by showing that response time depends on information available from local sequential structure. However, when Shimp and Friedrich varied the probability that a cue predicted one location or the other, which is called cue validity, when base rates of the two target locations were equal, there was no effect, on response time to the target, of changing amounts of information in the predictive cue. This result does not necessarily agree with the local predictability effects in Experiments 1 and 2 in which base rates of all three spatial locations were equal, and varying predictiveness did affect response time. At the present time, there are sufficient numbers of procedural details that are different in the two experiments to preclude constructive speculation about the causes of the difference beyond an obvious possibility that the $0.40 \mathrm{~s}$ SOA used by Shimp and Friedrich was sufficiently shorter than the 0.50 to $1.00 \mathrm{~s}$ in Experiments 1 and 2 so that the predictability effect became negligible, rather as it did in Experiment 2 when the RS interval was only $0.25 \mathrm{~s}$. We must 
acknowledge, however, that the lack of a cue predictability effect in spatial attention (Shimp \& Friedrich, 1993) may qualify the generality of the present effects of local predictability obtained in Experiments 1 and 2: It may not be universally true, perhaps even if the otherwise appropriate temporal conditions exist, for avian response times to different spatial locations to be determined in part by the degree to which the different locations can be predicted by immediately preceding events.

\section{General Discussion}

Our two overarching goals were to discover how serial response time performances of pigeons reveal sensitivity to local and/or global statistical information and to compare pigeon and human performances. Let us address these goals in the context of our answers to our four questions.

\section{Global Facilitation}

Experiments 1 and 2 together suggest that pigeons, like humans, on the average display global facilitation. It seems reasonable to provisionally interpret global facilitation in pigeons and humans in similar ways: Pigeons, like humans, learn something about the repeating sequence in which target locations appear, and that knowledge facilitates responding to target locations. Global facilitation tells us relatively little, however, about either the nature of the knowledge subjects acquire or how that knowledge facilitates responding.

Indeed, the term global facilitation can be misleading and therefore requires delicate treatment, especially because it is the basis for most of the neuropsychological uses of the Nissen and Bullemer (1987) serial response time task (e.g., Curran, 1998; Keele et al., 2003; Knopman \& Nissen, 1987, 1991; Nissen et al., 1987). As its name implies, global facilitation is a global phenomenon: It is global by definition in the sense that it involves aggregate performances. A reader could therefore be forgiven for mistakenly believing that global facilitation implies global learning in which global learning refers to learning a list as a whole in contrast to learning it in terms of its parts. Global facilitation by itself, however, does not imply that a subject has learned something holistic or global about an entire sequence. It simply says that performance on a repeating list with local structure is faster, for whatever reason, than in a random condition. Note that global facilitation is therefore actually defined in terms of a comparison based on the presence or absence of local statistical information. That is, the phenomenon consists of showing that global, aggregate performance depends on whether there is or is not local structure in the task. In short, global facilitation is defined in terms of a comparison that depends on the nature and amount of local statistical information and for that reason might actually be better termed a kind of local facilitation.

\section{Local Facilitation}

If global facilitation leaves almost entirely unclear what is actually learned, local facilitation sheds some clarifying light on the question. Experiments 1 and 2 substantially clarify what pigeons learn about repeating sequences. Local facilitation was obtained in both Experiments 1 and 2: Yes, pigeons' response times can be sensitive to implications of the structure of a list for local predictability of spatial locations. Local facilitation similar to that displayed by humans (Curran et al., 2001; Hunt \& Aslin, 2001) was found: Pigeons responded faster to locations that, given the immediately preceding one or two locations, were more likely to occur.

\section{Similarities Between Human and Pigeon Performances in Terms of Information Theory}

The specific way local list structure controlled local performance roughly approximated a familiar linear function in the literature on human information processing. This linear function, between response time to a spatial location and its first- and second-order local predictability, can be derived from the assumption that rate of information processing is constant (Hick, 1952; Hyman, 1953), that is, from the assumption that the rate at which a pigeon forms an anticipation of (activates a memory representation of), and prepares to respond to, the next location, is constant. The more predictable a location is, given the previous one or two locations, the faster the response to it. We know of no evidence suggesting that pigeons can remember an entire nine-item sequence such as that used here, yet they were able to extract local statistical information from the repetitive sequence of events and to use that information to prepare to respond adaptively to a spatial location.

Although local information was apparently processed in a manner consistent with information theory, global information was not. It is interesting to note that this contrast is reminiscent of that with human participants in which information theory has successfully described sensitivity of response times to local statistical information (Hick, 1952; Hyman, 1953) and has sometimes failed to describe corresponding effects of global statistical information on categorical judgment (Tversky \& Kahneman, 1990). Procedural differences between these two methods make comparison of the results they produce problematic. Fortunately, however, the recent article by Hunt and Aslin (2001) provides a more suitable basis for a comparison. As we saw in Experiment 1, their data roughly corresponded to the local results of Experiment 1, at least in the average slope of the regression line relating response time to local predictability. A similar correspondence was obtained between their data and the effects of global base rate in Experiment 3: They found that overall frequency was much less important to the determination of response time than was local predictability.

We confess to being surprised at the extent to which these and other quantitative features of human and pigeon sequential pattern learning are similar, in the context of the serial response time task. First, slopes of functions relating response time to local predictability were roughly similar for pigeons and humans. Second, optimal RS interval appears to be roughly similar for pigeons and humans (Stadler, 1995; Willingham et al., 1997). Third, both humans and pigeons appear to neglect base-rate information (Curran et al., 2001). We suspect it is far too early to suggest that both pigeons and humans process local information in serial response time tasks at similar rates, or even in similar ways, but these similarities between pigeon and human serial response time performances surely motivate additional research designed to clarify their generality and provide no support for the assumption of a general superiority of human over nonhuman animal sequential pattern learning. Indeed, these various similarities between pigeon and human performances might define the opportunity for the 
development of an animal model that could test proposals about the neurobiological basis of human serial learning (Keele et al., 2003). Further research should also examine the relation between the present successes and failures of information theory to other recent applications of information theory to avian visual cognition, which have suggested a role for amount of information in spatial arrays as a controlling variable (Young \& Wasserman, 2002).

The present analysis in terms of information theory suggests a third alternative to the two kinds of theories that have dominated the literature on nonhuman animal sequential pattern learning, associative learning theory (Wallace \& Fountain, 2002) and rule learning theory (Hulse, 1978). Information theory merits close attention because it provides an interpretation of how local statistical information governs behavior in both pigeons and humans; permits us to see that both pigeons and humans tend to ignore at least some forms of global statistical information; and, taken together with the results of Experiment 2, implies that both pigeons and humans have information-processing mechanisms that are similar in terms of their temporal dynamics. Neither associative theory nor rule learning theory has uncovered any of these similarities between animal and human sequential pattern learning, and it is not clear how either could describe the present results.

\section{A Speculation About the Plain English Meaning of Anticipating}

The ideas of expecting, intending, and anticipating are problematic in behavioral theory, because in everyday, nonscientific discourse, expectations are commonly and mistakenly taken to imply that the future can cause behavior, whereas behavioral accounts emphasize not the effect of the future on behavior but, of course, the effect of the past on behavior. That is, we look for explanations of an organism's behavior in its environmental history, not its environmental future. One presumably has no scientifically legitimate means of seeing or observing the future. Many researchers have tried, nevertheless, to develop tasks and performances by which natural-language ideas like anticipating or expecting could be scientifically investigated (e.g., Estes, 1943; Grant \& Kelly, 2001; Guthrie, 1935; Tinklepaugh, 1928; Tolman, 1932, 1959; Zentall, Steirn, \& Jackson-Smith, 1990). We agree with Skinner's (1989) suggestion that naturalistic, everyday situations presumably contributed to the development of everyday cognitive terms in the first place.

Thus, we would be remiss if we failed to note a strong connection between behavior in the present experiments and plain English meanings of anticipating and expecting. In Experiment 1, for example, an organism's environmental history with a particular nine-item list partly determined its behavior, and in plain English, one would say of a person having a similar experience that he or she more strongly expects a more likely location, and it would not be unusual to assume that more strongly expecting a location would facilitate responding to it. Analogously, we would say in plain English that a warning sign of an approaching but hidden left-hand curve is more effective in leading a speeding driver to expect and plan for the curve and to respond appropriately in advance of, or immediately after, seeing the curve come into view, if the warning sign is more legible, intelligible, and more advantageously placed in advance of the curve. Notice that both in our hypothetical everyday example of driving and in Experiments 1-3, anticipating might take place before and/or after the appearance of the stimulus itself. If the driver is familiar with the road the way our pigeons presumably were familiar with a structured list, then anticipating might involve both, but in the absence of data on eye movements and subtle body movements, it is impossible to tell (see also Fremouw, Herbranson, \& Shimp, 1998; Shimp \& Friedrich, 1993).

We would like to emphasize that by virtue of the fact that the present results may be interpreted in terms of anticipating in nonhuman animals, we have shown that anticipating is an orderly function of a quantitative dimension, the local statistical structure of the environment, and thereby opens up the process of anticipating in nonhuman animals for quantitative analysis, with all the attendant and well-known scientific advantages.

Because the present laboratory method captures some of the everyday, plain English meaning of expecting or anticipating, it may be possible to indirectly study how humans use plain English to talk about expectations by studying how pigeons behave in serial response time tasks. This possibility implies that neurobiological bases of what in ordinary language is meant by expecting might be studied through lesion, electrophysiological, and psychopharmacological approaches with the present avian method.

\section{Conclusion}

It no doubt would be asking too much to expect universal similarity in statistical learning mechanisms across an extremely wide range of species. The present results, however, encourage the view that the universality of the likelihood estimation problem animals face in nature may have generated surprisingly similar likelihood estimation mechanisms.

\section{References}

Blough, D. S. (1972). Recognition by the pigeon of stimuli varying in two dimensions. Journal of the Experimental Analysis of Behavior, 18, 345-367.

Blough, D. S. (1984). Form recognition in pigeons. In H. L. Roitblat, T. G. Bever, \& H. S. Terrace (Eds.), Animal cognition (pp. 277-289). Hillsdale, NJ: Erlbaum.

Blough, P. M. (1996). Priming during multiple-target search: The cumulative effects of relative target frequency. Animal Learning \& Behavior, 24, 394-400

Blough, P. M. (1997). Searching for one or many targets: Effects of extended experience on the runs advantage. Journal of Experimental Psychology: Animal Behavior Processes, 24, 98-105.

Cohen, J. (1992). A power primer. Psychological Bulletin, 112, 155-159.

Cook, R. G. (2001). Avian visual cognition. Retrieved December 15, 2003, from Tufts University Web site: http://www.pigeon.psy.tufts.edu/avc

Curran, T. (1998). Implicit sequence learning from a cognitive neuroscience perspective: What, how, and where? In M. A. Stadler \& P. A. Frensch (Eds.), Handbook of implicit learning (pp. 365-400). Thousand Oaks, CA: Sage.

Curran, T., Smith, M. D., DiFranco, J. M., \& Daggy, A. T. (2001) Structural influences on implicit and explicit sequence learning. In D. L. Medin (Ed.), The psychology of learning and motivation (Vol. 40, pp. 147-182). San Diego, CA: Academic Press.

Dunn, D. S. (2001). Statistics and data analysis for the behavioral sciences. New York: McGraw-Hill.

Estes, W. K. (1943). Discriminative conditioning: I. A discriminative property of conditioned anticipation. Journal of Experimental Psychology, 32, 150-155.

Estes, W. K. (2002). Traps in the route to models of memory and decision. Psychonomic Bulletin \& Review, 9, 3-25. 
Fountain, S. B. (1990). Rule abstraction, item memory, and chunking in rat serial-pattern tracking. Journal of Experimental Psychology: Animal Behavior Processes, 16, 96-105.

Fremouw, T., Herbranson, W. T., \& Shimp, C. P. (1998). Priming of attention to local or global levels of visual analysis. Journal of Experimental Psychology: Animal Behavior Processes, 24, 278-290.

Frensch, P. A., \& Miner, C. S. (1994). Effects of presentation rate and individual differences in short-term memory capacity on an indirect measure of serial learning. Memory \& Cognition, 22, 95-110.

Garner, W. R. (1962). Uncertainty and structure as psychological concepts. New York: Wiley.

Grant, D. S., \& Kelly, R. (2001). Anticipation and short-term retention in pigeons. In R. G. Cook (Ed.), Avian visual cognition. Retrieved December 15, 2003, from Tufts University Web site: http://www.pigeon .psy.tufts.edu/avc

Guthrie, E. R. (1935). The psychology of learning. New York: Harper \& Row.

Hays, W. H. (1973). Statistics (3rd ed.). New York: Holt, Rinehart \& Winston.

Herbranson, W. T. (2000). Cognitive dissociation of memory systems: Implicit and explicit memory in pigeons (Columba livia). Unpublished doctoral dissertation, University of Utah.

Hick, W. E. (1952). On the rate of gain of information. Quarterly Journal of Experimental Psychology, 4, 11-26.

Hulse, S. H. (1978). Cognitive structure and serial pattern learning by animals. In S. H. Hulse, H. Fowler, \& W. K. Honig (Eds.), Cognitive processes in animal behavior (1st ed., pp. 311-340). Hillsdale, NJ: Erlbaum.

Hunt, R. H., \& Aslin, R. N. (2001). Statistical learning in a serial reaction time task: Access to separable statistical cues by individual learners. Journal of Experimental Psychology: General, 130, 658-680.

Hyman, R. (1953). Stimulus information as a determinant of reaction time. Journal of Experimental Psychology, 65, 39-46.

Keele, S. W., Ivry, R., Mayr, U., Hazeltine, E., \& Heuer, H. (2003). The cognitive and neural architecture of sequence representation. Psychological Review, 110, 316-339.

Knopman, D. S., \& Nissen, M. J. (1987). Implicit learning in patients with probable Alzheimer's disease. Neurology, 37, 784-788.

Knopman, D. S., \& Nissen, M. J. (1991). Procedural learning is impaired in Huntington's disease: Evidence from the serial reaction time task. Neuropsychologia, 29, 245-254.

Machado, A. (1994). Polymorphic response patterns under frequencydependent selection. Animal Learning \& Behavior, 22, 53-71.

Maki, W. S., Moe, J. C., \& Bierley, C. M. (1977). Short-term memory for stimuli, responses, and reinforcers. Journal of Experimental Psychology: Animal Behavior Processes, 3, 156-177.

Nissen, M. J., \& Bullemer, P. (1987). Attentional requirements of learning: Evidence from performance measures. Cognitive Psychology, 19, 1-32.

Nissen, M. J., Knopman, D. S., \& Schacter, D. L. (1987). Neurochemical dissociation of memory systems. Neurology, 37, 789-794.

Posner, M. I., Snyder, C. R. R., \& Davidson, B. J. (1980). Attention and the detection of signals. Journal of Experimental Psychology: General, 109, $160-174$.

Shaw, M., \& Shaw, P. (1977). Optimal allocation of cognitive resources to spatial location. Journal of Experimental Psychology: Human Perception and Performance, 3, 201-211.
Shimp, C. P. (1973). Sequential dependencies in free responding. Journal of the Experimental Analysis of Behavior, 19, 491-497.

Shimp, C. P. (1976). Organization in memory and behavior. Journal of the Experimental Analysis of Behavior, 26, 113-130.

Shimp, C. P., \& Friedrich, F. J. (1993). Behavioral and computational models of spatial attention. Journal of Experimental Psychology: Animal Behavior Processes, 19, 26-37.

Skinner, B. F. (1989). The origins of cognitive thought. American Psychologist, 44, 13-18.

Stadler, M. A. (1995). The role of attention in implicit learning. Journal of Experimental Psychology: Learning, Memory, and Cognition, 21, 674685.

Terrace, H. S. (2001). The comparative psychology of serially organized behavior. In R. G. Cook (Ed.), Avian visual cognition. Retrieved December 15, 2003, from Tufts University Web site: http://www.pigeon .psy.tufts.edu/avc

Tinklepaugh, O. L. (1928). An experimental study of representative factors in monkeys. Journal of Comparative Psychology, 8, 197-236.

Tolman, E. C. (1932). Purposive behavior in animals and men. New York: Appleton-Century-Crofts.

Tolman, E. C. (1959). Principles of purposive behavior. In S. Koch (Ed.), Psychology: A study of a science: Vol. 2. General systematic formulations, learning, and special processes (pp. 92-157). New York: McGraw-Hill

Tversky, A., \& Kahneman, D. (1990). Judgment under uncertainty: Heuristics and biases. In P. K. Moser (Ed.), Rationality in action: Contemporary approaches (pp. 171-188). New York: Cambridge University Press.

Vakil, E., Kahan, S., Huberman, M., \& Osimani, A. (2000). Motor and non- motor sequence learning in patients with basal ganglia lesions: The case of serial reaction time (SRT). Neuropsychologia, 38, 1-10.

Wallace, D. G., \& Fountain, S. B. (2002). What is learned in sequential learning? An associative model of reward magnitude serial-pattern learning. Journal of Experimental Psychology: Animal Behavior Processes, 28, 43-63.

Welford, A. T. (1968). Fundamentals of skill. London: Methuen.

Welford, A. T. (1977). Serial reaction times, continuity of task, singlechannel effects, and age. In S. Dornic (Ed.), Attention and performance (Vol. 6, pp. 79-97). Hillsdale, NJ: Erlbaum.

Willingham, D. B., Greenberg, A. R., \& Thomas, R. C. (1997). Responseto-stimulus interval does not affect implicit motor sequence learning, but does affect performance. Memory \& Cognition, 25, 534-542.

Young, M. E., \& Wasserman, E. A. (2002). Detecting variety: What's so special about uniformity? Journal of Experimental Psychology: General, 131, 131-143.

Zentall, T. R., \& Clement, T. S. (2002). Memory mechanisms in pigeons: Evidence of base-rate neglect. Journal of Experimental Psychology: Animal Behavior Processes, 28, 111-115.

Zentall, T. R., Steirn, J. N., \& Jackson-Smith, P. (1990). Memory strategies in pigeons' performance of a radial-arm-maze analog task. Journal of Experimental Psychology: Animal Behavior Processes, 16, 358-371.

Received December 20, 2002

Revision received June 25, 2003

Accepted June 26, 2003 